\title{
George A. Garratt, FORESTRY EDUCATION IN CANADA
}

\author{
Canadian Institute of Forestry, 1971, Pp. 408, $\$ 15.00$
}

J. B. McLeish*

When B. E. Fernow, then head of the College of Forestry at Cornell, arrived at Queen's University, Kingston, on a snowy January day in 1903 to deliver a series of lectures on forestry at the School of Mining, he perhaps unwittingly inaugurated forestry education in Canada. At all events, four years later Fernow was invited to become the first Dean of the Faculty of Forestry at the University of Toronto, thus joining the group of founders and innovators who in retrospect lend a special interest to the story of Canadian higher education before World War One. Three other universities subsequently set up facilities for forestry education over the period 1908-1921 (New Bruswick, Laval, and British Columbia), and these four institutions have remained the centres of forestry education in Canada. Nor does Dr. Garratt's report, commissioned by the Canadian Institute of Forestry, recommend an increase in this number. His concerns, in this very comprehensive, perhaps watershed survey of the past history, are rather with how the existing faculties can successfully cope with change; and how the now numerous allied professional facilities can also be successfully developed to meet the demands of future shock. Garratt brought to his task expert and objective insights acquired as professor and dean, and now dean emeritus at Yale, and these are in evidence throughout this excellent study.

All professions and professional schools suffer from certain stereotyped conceptions held about them by lay people, and in the case of forestry perhaps the most prominent is the image of the forester as the outdoors guardian of Canada's timber resources. This single-hearted and partially correct picture creates certain problems at the admissions end of forestry study where, according to the authoritative American

* JOHN B. McLEISH: Professor of Adult Education, Ontarino Institute for Studies in Education and Executive Vice-Chairman Kellogg Foundation/OISE Professional Education Project. 
study by S. T. Dana and E. W. Johnson, Forestry Education in America To-day and To-morrow, Washington: Society of American Foresters, 1963, "association with the outdoors" was clearly the dominant overall factor among the freshmen of 14 selected forestry schools in choosing general forestry. A more sophisticated stereotype is of the forester as wood-products engineer, with the prestige which membership in a major profession implies; but this view also ignores the transformation which has taken place in forestry education in recent years extending it far beyond the range of a useful subdivision of conventional engineering.

The picture that emerges from Dean Garratt's very detailed study is of a practice field being transformed by the ecological concerns of governments and the lay public and of some sectors of the forest industries as well. The harvesting phase in woodland operations will remain, and professional foresters will continue to be in demand for various aspects of forest management and utilisation. But an array of new roles has come forward concerned with what might be called environmental forestry, involving a new breed of forester, a "resource generalist." In this category the forester joins a group of practitioners and theoreticians from other disciplines: biologists, geographers, landscape architects, conservationists, economists, political scientists, and soils and water resource specialists; and if the forestry graduate is to maintain his place as a leader in the new domain of public concern, he must be educated in new ways for new roles. In addition, a major need has emerged for forest scientists, that is for members of the forestry profession specifically concerned with fundamental and applied research related to the underlying biological, mathematical, economic and social aspects of forestry. The first implications here are for graduate work in forestry, but Garratt sees beyond these to the responsibilities which are laid upon undergraduate forestry education as a first ground to develop responses to these new needs in interdisciplinary and applied scientific studies.

Thus the curtain rises on a scene already familiar to the student of professional education in our time, of the great professions and their schools and of their early efforts to contend with the ramifications of present and future shock. All the components are here : the effects of the knowledge explosion, which so far as the student is concerned might better be called the knowledge implosion; the need to consider the role of liberalising and theoretical studies in curricula preoccupied with skills and techniques; the need to assess what part specialisation should play in senior undergraduate professional programmes ; the role of students in curricular planning; the need to examine more rigorously what later difficulties are distributed across the whole faculty programme by largely unselective admissions procedures; the need to investigate better teaching/learning strategies; the need to explore both the merits and the possible inadequacies and pitfalls of interdisciplinary classes; the more successful interplay of campus and field, and the better conceptualisation and use of the role of the practitioner/teacher; the problem of how to help develop the continuing learner and how to inhibit obsolescence. 
Among the rather massive array of facts, tables and charts by which the author presents his study (and which nonetheless do not impede the general flow of the argument), Dean Garratt's central these come through persistently and clearly. The future of forestry education lies with two great obligations imposed by the nature of the modern world and the modern profession: namely, to educate for diversity of roles and to educate for change. The responsibility to educate for a diversity of major careers in forestry arises from a concept of the profession as involved in "a complex of technological, political, economic, and social implications regarding the management of forested land and associated natural resources and the utilization of the derived products and services." (369) The future will demand "an adequate number of generalists, more broadly educated as land and resource managers than in the past", and also "forest scientists", who will be drawn typically from the ranks of "undergraduates who have majored in biology, chemistry, physics, mathematics, economics, and even the other social sciences." Thus education for diversity is certain to call increasingly for not only more generalised study, but for multidisciplinary work at numerous points of both the undergraduate and graduate curricula. (30) Garratt recommends an acceleration of cross-appointments and exchange use of facilities with other faculties and departments. At the same time, the interdisciplinary instruction made available through the co-operation of these other teaching areas "must be relevant to the needs of forestry students." How often has one heard this before from health science complexes and theological clusters?

Education to cope with change raises here in the domain of forestry education a number of the issues and possible solutions found elsewhere among the professions in transformation. For example: how far should specialisation go in the undergraduate years ? To Garratt, the peril in undergraduate specialisation lies in the possibility that the programmes will tend to be oriented toward current and projected employment opportunities rather than to the long-range needs of the graduates. The fact seems to be (he argues) that one cannot foresee the knowledges and skills needed to cope with change, explicitly to be a continuing learner and problem-solver. (He sees a role for an early experience or foretaste of graduate specialisation, perhaps through the device of the "areas of concentration" developed in senior year at certain forestry faculties.)

Garratt is absorbed not only with the problem of obsolescence per se, but with the inability of many present foresters to cross a mid-career plateau to the higher levels of management and direction. The high proportion of applied courses to which they have been exposed makes the transition easy from campus to field; but by the same process frequently make it difficult if not impossible for them to make the adjustments and reconceptualisations which continuous change demands in industry and government. Yet the need is not for a few courses salted and peppered into the curriculum (the analogy is E.W. Hartung's) but for a careful interdigitation of humanistic studies with the professional work; a radical new emphasis on theoretical as against rocational knowledge, and a de-emphasis on didactic fact-learning in the sphere of teaching/ 
learning strategies. Garratt quotes J.A. Zivnuska with approval : "In a world of change only a theoretical education is practical".

Coping with the relentless phenomenon of change also means a more expert use of field education for undergraduate forestry students than has been the case hitherto. Field education has two obvious roles in promoting adaptability and growth in the future professional person, (not only in forestry education) : directly, by making available insights and understandings not only of field processes, which rapidly pass, but of human relationships and the human condition, which do not; and indirectly by providing extra time within the regular timetable for theoretically-based studies. In the case of forestry education, the custom has generally been to intersperse so-called field instruction across the academic year, much as teacher education faculties do ; and to provide a summer camp, or more commonly a mandated summer employment experience - often with the lamentable results familiar to the theological educators, of an unsystematic, unplanned, and unproductive summer period. What Garratt seeks is for the faculties of forestry "to consider turning over to the operating groups in industry and government virtually the entire responsibility for performing the necessary vocational training services" - thus enabling the faculties to "devote their attention to full professional education." (260) In this position, he is fortified by the returns on a questionnaire received back from over 600 practising foresters in which almost the total consensus $(98.4 \%)$ was in favour of summer employment that was carefully planned, intelligently supervised, and co-ordinated with both field organisation and faculty curriculum.

A section of the Garratt Report of considerable fascination to colleagues from other professional disciplines is his chapter on "Undergraduate Admissions". There the authors deals with unusual forthrightness (for the topic), with the possibly crucial nature of the admissions process in undergraduate forestry education, and with the extent to which haphazard or indifferent admissions procedures can impair the ongoing life of a faculty - and beyond this, the effectiveness of much of its innovation. Dean Garratt starts where few discussions of admissions to professional faculties normally do - with the field practitioner

"The reported failures of professional foresters on the job are seldom for the reason of lack of technical competence," he says. "Rather the inadequacies are much more often related to lack of ability to communicate effectively, lack of understanding of human behaviour and consequent inability to work effectively with other people, lack of imagination and perception and of resilience and capacity to adapt to change, unwillingness to assume enlarged responsibilities, and, especially in the business field, lack of understanding of basic business principles." (263) And he suggests that "an effective admissions policy should serve to screen out the most likely failures in a profession that deals with people fully as much as with trees." (263) Many academics would heartily echo the need but distrust the process ; yet many others who have sought constructive innovation in their faculties might support Garratt on both counts, in the 
light (or darkness) of graduates who seem impervious to continuous and imaginative growth, and who in addition were manifestly uninterested as undergraduates in such of anything beyond credits and marketable skills. The future programmes Garratt envisages call for superior students as well as superior faculty and resources.

It is not perhaps a surprise to learn that academically superior students have been the exception rather than the rule in the forestry faculties. What is a surprise is the high attrition rate, the surprise perhaps being engendered by the persistent stereotype of forestry education as a kind of straightforward manly field typically chosen by sold hard-working young men mostly from the rural areas. The attrition rate was no less than $50 \%$ for all four Canadian Faculties of Forestry combined, with a range of 26 to $70 \%$ reported by the individual schools. (56) In fact, until recently the "rural areas" origin of most of the students was seemingly a contributing factor to attrition; this distribution is now changing as more and more students come from middle and large-sized cities, and as rural schools consolidate into simulated city schools. What does seem to be a good omen for the future, Garratt suggests, (264) is that as high school graduates and arts and science undergraduates who choose forestry education become more and more "academically sophisticated", there may be a built-in guarantee of breadth; and he might have added, of newer and more productive personal styles of learning which with better entering performance may help produce a forestry graduate of the future who is more open to change, more able to advance to positions of significant leardership, and more conscious of the claims and the pleasure of lifelong learning.

The 27 annotated recommendations which conclude the Report are less interesting than the main body of the text, but from the text and the recommendations together one can gain a view of a number of fields of importance particularly to the profession itself : library facilities, specific current programmes, graduate education, technical training, continuing education, and two or three others. One disappointment is the extremely limited treatment given to teaching strategies and aids. What is said is excellent, including the reference to the need and the certainty of arrival of student self-learning techniques and greater access to electives and interdisciplinary study within the next ten years. However, there is a whole repertoire of new instructional approaches actually now being employed in different major fields and schools of professional education : multidimensional instruction; temporary systems (including modular curricula which permit all kinds of new patterns for small group and individualised learning); new strategies for removing redundancy and didactic waste from the conventional lecture; new forms of tutor/student learning; and new provisions for intelligent and productive self-learning; new sensible ways of employing programmed learning. There is much to be learned from interprofessional consultations in these matters, as well as in planning sessions on content done by interdisciplinary co-operation. Innovations in curricula styles and teaching/learning strategies are not just the result of siturations of non-motivation, learner fatigue, and impossible traffic jams of facts old and new : they 
are the progenitors of new ideas and practices which can release both professor and student from certain undoubted drudgeries and inefficiencies, and set in action some very useful instruments against professional obsolescence.

In summation, however, Forestry Education In Canada is a fine strong study of a professional field which is usally out of the sight of the commentators and philosophers of professional education; yet one, which, when brought comprehensively into view as in this Report, is full of interest and stimulus, and will clearly have some contributions to make to the theory and practice of professional education in Canada. 